\title{
Beyond OCRA: Predictive UL-WMSD Risk Assessment for Safe Assembly Design
}

\begin{abstract}
In terms of occupational safety, one of the most important areas to consider is that of Upper-Limb Work-related MusculoSkeletal Disorders (UL-WMSDs), i.e. work-related disorders due to biomechanical overload of the upper limbs caused by protracted movements and/or repeated efforts throughout the workday. To estimate the risk associated with these disorders, the method known as the OCRA (OCcupational Repetitive Actions) Index is universally accepted; based on observation, it provides an index whose value is related to the expected percentage of pathological cases among the entire working population. This work introduces a different perspective to the problem in order to provide designers with a method - PRASAD: Predictive Risk Assessment for Safe Assembly Design - that makes them aware of the issues related to UL-WMSDs, starting from the earliest stages of the design of a new product and the related assembly workstation, well earlier than observing the activities associated to its production, that is when the assembly workstation is fully set and running. The main advantage of the method lies in the outcome, the PRASAD Index, which is fully comparable with the OCRA Index, so that the proposal leverages on the well-known OCRA standard approach. The new method, aimed at a use in the design phase (of a new workstation for a new product), is potentially useful for a conventional risk assessment of existing workstations as well: it combines the rapidity of a checklist for the initial screening with a level of detail that is characteristic of advanced methods, such as the OCRA Index. Finally, PRASAD represents an innovation in the risk assessment of UL-WMSDs because of its feature of modelling the concept of "Technical Actions", which enables estimating (and taking into account) the repetitiveness of tasks, based on technical design and production management data.
\end{abstract}

Keywords: safety, upper-limb work-related musculoskeletal disorders, ULWMSD, OCRA Index, assembly, design

\section{Introduction}

With the evolution of the study of safety and the introduction of new norms, analysis of the evaluation of risk is becoming more and more important. Among the various fields of study related to workplace safety, the interaction between 
workers and the workplace plays a fundamental role. This problem can be decomposed into a myriad of aspects, one of which is the object of this text: the study of the risk of biomechanical overload of the upper limbs, which is the cause of certain diseases, defined as UL-WMSDs (upper-limb work-related musculoskeletal disorders) (Simoneau et al., 2003). At the same time, there has been a proliferation of different methods designed to estimate the associated risk (as further developed in the following).

This interest in these issues is now widespread internationally and is motivated by the continuous increase in work-related musculoskeletal disorders of the upper limbs: to quantify this increase, we have collected data regarding occupational diseases reported by INAIL (the Italian Workers' Compensation Authority) in Italy (INAIL, 2013) (Fig. 1, which shows the number of occurred, not necessarily compensated, work-related diseases). The trend is towards a substantial increase in general, and as for UL-WMSDs in particular. This is the reason for the increasing importance of methods that enable the assessment of the risk of contracting these pathologies.

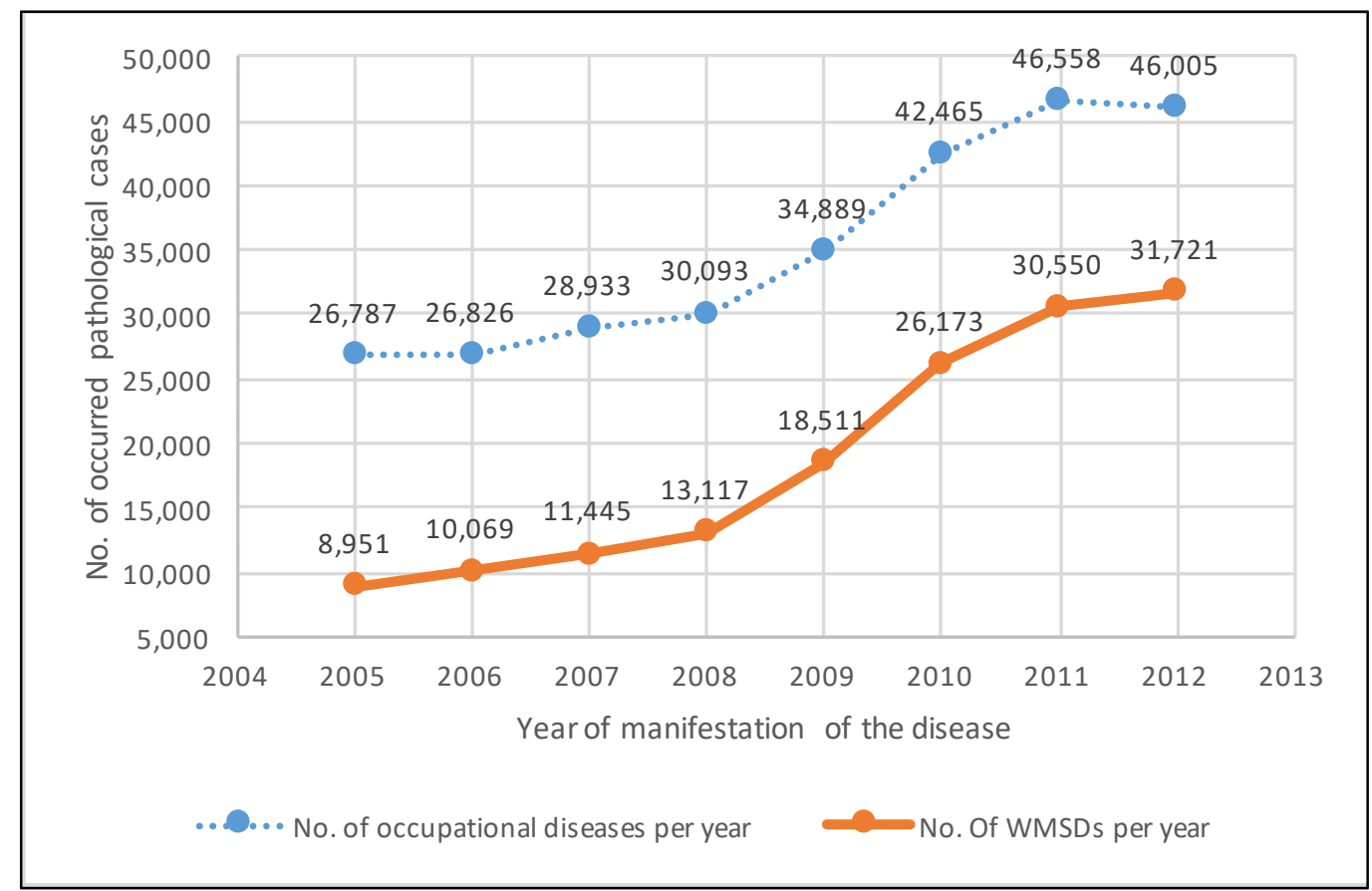

Figure 1 - Number of occurred (not necessarily compensated) work-related diseases (particularly musculoskeletal ones) reported by INAIL in Italy for all working areas from 2005 to 2012

It is also important to know that there are legal requirements that force owners/managers to intervene in matters of safety to ensure the health of the workers. In Italy, the "Testo Unico" in matters of safety, issued through 
Legislative Decree $81 / 08$, is the reference legislative decree that must also be observed for the prevention of UL-WMSDs. It provides, in art. 15 (Legislative Decree 81/08, 2008), that the employer takes general measures for the protection of workers, which include:

“...il rispetto dei principi ergonomici nella concezione dei posti di lavoro, nella scelta delle attrezzature e nella definizione dei metodi di lavoro e produzione, anche per attenuare il lavoro monotono e ripetitivo."

(that is:) ...the respect of ergonomic principles in the conception of the workplace, in the selection of the equipment and in the definition of the methods of work and production, as well as the minimization of monotonous and repeated jobs.

Article 28 (Legislative Decree 81/08, 2008) states that the evaluation of risks must include all risks related to the health and safety of workers. In particular, repeated movements and efforts are considered causes of risks for health, and therefore the employer is obliged to analyse this type of risk.

Moreover, a voluntary technical norm has recently been adopted by ISO, which is considered the reference for operating evaluations of this kind. This norm is ISO 11228-3; Ergonomics - Manual handling - Handling of low loads at high frequency (ISO 11228-3, 2007) and it is directly reported by Legislative Decree 81/08; here we can find the suggested (favourite) method: OCRA (OCcupational Repetitive Actions). The technical standard ISO 11228-3 is also the reference in the processes of risk assessment of repeated movements and efforts of the upper limbs for the Lombardy region (one of the twenty administrative regions of Italy, in the northwest of the country; specifically, the major contributor to Italian GDP, summing $21.6 \%$ of the national GDP in 2015 - see Banca d'Italia 2016 -, mainly due to a flourishing manufacturing industry).

The OCRA method is now considered not only the Italian standard, but also the European and international one, in addition to a list of well-known available methods (in the following, some examples are reported): ACGIH HAL TLV (American Conference of Governmental Industrial Hygienists, 2004), Checklist OSHA (Schneider, 1995), OREGE (Hervet and Vallerey, 2001), RULA (McAtamney and Corlett, 1993), Job Strain Index (Moore and Garg, 1995), and so on. The purpose of this paper is to highlight the limits of the existing methods, including OCRA, and to devise a new method that will eventually bridge the gaps.

\section{Purpose}

Currently, safety experts have to appraise the risk of UL-WMSDs using the methods available in order to provide risk indexes that indicate the level of criticality of a particular job or task. Nonetheless, we live in a time when companies need to innovate constantly and cannot afford to rely on a static and 
antiquated product lines or workstations. We are therefore experiencing a continuous proliferation of new technologies and products. The heart of innovation in industry lies in the stages of new product and process design. As far as the most renowned industrial engineering handbooks (e.g., Salvendy, 2001 as for the workstations), new product development handbooks (e.g., Loch and Kavadias, 2008 as for the new product design), and professional experience of the authors are concerned, the design of a new workstation comes after the design of a new product, mainly in terms of operational performance, whilst whatever has to do with UL-WMSD Risk Assessment is typically performed separately, once the workstation itself has been fully set. Each of the two aspects follows its own path without the ability to interface with each other. However, in principle there is no reason for thinking that design (of the product and of the workstation for the sake of operational performance) and safety cannot be immediately considered in a merged way. There is no doubt that intervening later in the causes of risk of ULWMSDs (that is, once a workstation is fully set and running) costs much more than intervening in the design phase (that is, no need of buying new machines/equipment and/or paying for the construction and set up works in order to deal with unacceptable risk level). This is not to say that existing methods cannot help in some way in the design. This possibility is partly evident in the method of the OCRA Index, but this only provides useful data in relation to redesigning the workplace, particularly when the product to produce/assemble (and the associated tasks) does not change significantly. Still, it has to do with redesigning, not designing. We must also wonder whether the risk sources are connected exclusively to the peculiarities of the workplace and to the process: it is logical to expect that the design features of the product that we are going to produce/assemble may influence the risk associated with the job. Let us consider, for example, a product that is difficult to assemble, with joints or screws required in areas that are difficult to access: the operator will have to work maintaining improper postures or exerting excessive force. This will increase the intrinsic risk of the task under consideration. It is also reasonable to suppose that the greater the technical complexity of the product, the more likely it is that the operator will have to carry out a number of difficult operations (unless automated), which in turn will make the tasks critical from the point of view of UL-WMSDs. These examples highlight the possibility and opportunity of being able to predict risk factors at the product and workstation design level. In fact, predicting the risk associated with the tasks before setting up the whole workstation, will imply avoiding future really expensive redesign of a fully set and running workstation, aimed at restoring the risk to within acceptable limits.

\section{Available methods and limits}

In order to set the background of our proposal, we have taken into account a number of methods for the study of risk of UL-WMSDs, considering as a 
paradigmatic domain of application an assembly workstation together with its tasks: ACGIH HAL TLV, OSHA, OREGE, RULA, Job STRAIN INDEX, TR ISO12295 (ISO/TR 12295, 2014), Checklist OCRA (Colombini et al., 2013), OCRA Index. These methods - among a wider set of methods (for a relatively recent full list, see Bhattacharya and McGlothlin, 2011) - were selected by the authors based on both their acceptance in Italy (from a technical/legal viewpoint) and the willingness of experts to use them (based on a focus group with 2 researchers and 3 professionals (average experience: 15 years) working as consultants/advisors for well dispersed companies in terms of size and industrial sector, still manufacturing companies); based on the focus group, we also carried out a comparison of the selected methods to find the most fitting (if any) our scope.

Table 1 - Comparison of methods for risk assessment of UL-WMSDs, based on the factors to be taken into account, considering as a paradigmatic domain of application an assembly workstation together with its tasks; source: focus group

\begin{tabular}{|c|c|c|c|c|c|c|c|c|}
\hline & $\begin{array}{l}\text { ACGIH } \\
\text { HAL } \\
\text { TLV }\end{array}$ & OSHA & OREGE & RULA & $\begin{array}{l}\text { STRAIN } \\
\text { INDEX }\end{array}$ & $\begin{array}{l}\text { TR ISO } \\
12295\end{array}$ & $\begin{array}{l}\text { C.L. } \\
\text { OCRA }\end{array}$ & $\begin{array}{l}\text { OCRA } \\
\text { INDEX }\end{array}$ \\
\hline Postures & $\begin{array}{c}\text { Yes, but } \\
\text { shoulder } \\
\text { s }\end{array}$ & $\mathrm{X}$ & $\mathrm{X}$ & $\begin{array}{c}\text { Yes, but } \\
\text { hand grip }\end{array}$ & $\begin{array}{l}\text { Only } \\
\text { wrist- } \\
\text { hand }\end{array}$ & $\mathrm{X}$ & $\mathrm{X}$ & $\mathrm{X}$ \\
\hline Frequency & $\mathrm{X}$ & & & $\begin{array}{l}\text { Limited } \\
\text { relevance }\end{array}$ & $\mathrm{X}$ & $\mathrm{X}$ & $\mathrm{X}$ & $\mathrm{X}$ \\
\hline Strength & $\mathrm{X}$ & $\mathrm{X}$ & $\mathrm{X}$ & $\begin{array}{l}\text { Limited } \\
\text { relevance }\end{array}$ & $\mathrm{X}$ & $\mathrm{X}$ & $\mathrm{X}$ & $\mathrm{X}$ \\
\hline Recovery & & & & & & $\mathrm{X}$ & $\mathrm{X}$ & $\mathrm{X}$ \\
\hline $\begin{array}{l}\text { Repetitivenes } \\
\mathrm{s}\end{array}$ & & $\mathrm{X}$ & $\mathrm{X}$ & $X$ & & $\mathrm{X}$ & $\mathrm{X}$ & $\mathrm{X}$ \\
\hline Complem. & & $\begin{array}{l}\text { Vibratio } \\
\mathrm{n} \text { and } \\
\text { microcli- } \\
\text { mate }\end{array}$ & & & & & $\mathrm{X}$ & $\mathrm{X}$ \\
\hline
\end{tabular}

In principle, any observation-based tool, for example RULA and OCRA, could be used in a pre- and post- redesign (that is, when some features in terms of product and/or process has to be changed) scenario analysis, pretending that the assessors are able to predict the observable results. As reported in Table 1 (drafted during the focus group), the factors considered are improper postures of upper limbs, frequency, strength, recovery, Repetitiveness and complementary factors. 
Each method has its strengths but only Checklist OCRA and the OCRA Index consider all the factors (which is a significant gap); in particular, the Checklist is the fast version of the OCRA Index. In addition, both Checklist OCRA and the OCRA Index are the most applied methods as far as the experience of the professionals involved is concerned. Thus, when it comes to the design of a new product and associated workstation, even if the OCRA Index provides data that can only be used during the redesign of an assembly workstation for an existing product (yet, not for the case of a brand-new product and associated brand-new workstation), the focus group agreed that the OCRA index is by far the most promising basis for further development of a tool to predict risk factors at the product and workstation design level.

The method that we propose in the following has therefore as its reference the OCRA Index because it is particularly complete and because it is used as the European standard (EN 1005-2) (BSI, 2003) and the international one (ISO 11228-3, 2007). In addition, as demonstrated in various researches (Madhi et al., 2013; Sala et al., 2010), the OCRA Index provides results that are consistent with other methods, resulting in being certainly more complete. The new method follows the same logic (and acronyms) as the method of the OCRA Index, thereby leveraging on the well-known OCRA standard approach.

\section{Beyond OCRA: Predictive UL-WMSD Risk Assessment for Safe Assembly Design}

The new method stems from a very clear necessity, but with roots firmly fixed in the foundations established by the most developed and widespread method, the OCRA Index. The ultimate purpose is to create a method that enables the risk of UL-WMSDs associated to a (new) assembly workstation to be estimated, starting from the design data of a brand-new product. Given the benchmark (OCRA Index), an additional purpose will be to ensure full compatibility between the results of the new method and those of the OCRA Index, in order to make them immediately and easily comparable.

We started from the basic formulation of the OCRA Index [1], which is actually a risk indicator:

OCRA Index $=\frac{A T A}{R T A}$

where:

ATA $=$ Actually performed Technical Actions;

RTA $=$ Recommended Technical Actions.

Retaining the logic, we can see the new index as the ratio between two elements: the numerator is called PTA, Predicted Technical Actions, and it represents a 
certain number of actions that are assumed to be performed during the operations related to the assembly during a certain task; the denominator is still RTA, Recommended Technical Actions, but it needs a conceptually different approach to its assessment.

We synthesize the idea in the following formula related to IR (Risk Indicator, as named in Italian in OCRA), which is the new Risk Indicator [2]:

$R I=\frac{P T A}{R T A}$

where:

PTA $=$ Predicted Technical Actions;

RTA $=$ Recommended Technical Actions (same as in OCRA).

It is useful to clarify that the proposed method does not provide separate indices for the two upper limbs. This feature is, however, present in the OCRA Index. The reason is that the method is intended to be applied in the design phase and so it is impossible to attribute the individual actions to the involved upper limb; in fact, we do not have the opportunity to observe the conduct of actual operations, until the assembly workstation is fully set and running (at that stage, by the way, the proposed method immediately enables the calculation of a full OCRA Index). Moreover, this level of detail is typically not yet taken under consideration at a design phase (typically, the designer does not know exactly which employee(s) will be involved). We consider the risk index to be an estimator for the dominant limb - in the case of asymmetric workload for the two arms.

The PTA must represent the number of actions of the real assembly. To enable a correct count, it is necessary to model the operational reality. We adopt the idea of differentiating the technical actions into three distinct types:

- BTA - Basic Technical Actions;

- TAS - Technical Actions of Screwing;

- TAE - Technical Actions on Equipment.

They lead to a particular definition of PTA [3]:

$P T A=\sum_{j=1}^{n}\left[\left(B T A_{j}+T A S_{j}+T A E_{j}\right) N P\right]$

where:

$j=$ generic repeated task of the upper limbs;

$n=$ number of repeated tasks in the shift;

$B T A j=$ number of Basic Technical Actions for the $\mathrm{j}$-th task; 
$T A S j=$ number of Technical Actions of Screwing for the $\mathrm{j}$-th task;

$T A E j=$ number of Technical Actions on Equipment for the $j$-th task;

$\mathrm{NP}=$ number of assembled products or work-cycles.

The RTA is similar to that proposed with the OCRA Index [4]:

$R T A=\sum_{j=1}^{n}\left[C F\left(F o_{M j} P o_{M j} R e_{M j} A d_{M j}\right) D_{j}\right]\left(R c_{M} D u_{M}\right)$

where:

- $\boldsymbol{C F}=$ frequency constant of technical actions per minute recommended in reference conditions, equal to 30 actions/min (same logic and acronym as for the OCRA Index);

- $\boldsymbol{F} \boldsymbol{o}_{M j}=$ multiplier of the Force, not foreseeable at the design stage. It will be taken into account through likely scenarios in section 5; earlier than section 5 , the Force multiplier will be considered as in "optimal conditions", that is, equal to " 1 ";

- $\boldsymbol{P} \boldsymbol{o}_{M j}=$ multiplier of the Posture, not foreseeable at the design stage. It will be taken into account through likely scenarios in section 5; earlier than section 5, the Posture multiplier will be considered as in "optimal conditions", that is, equal to " 1 ";

- $\boldsymbol{R} \boldsymbol{e}_{M j}=$ multiplier of the Stereotypy, estimated by the percentage of the cycle time characterized by gestures or movements repeated identically or if the cycle time is extremely short. The detailed values, according to the same logic (and acronym) as for the OCRA Index, are reported in Table 2;

- $\boldsymbol{A d}_{\boldsymbol{M j}}=$ multiplier of the Complementary features, takes into account some additional factors such as vibration, cold temperatures, difficult tasks, ... (same logic and acronym as for the OCRA Index);

- $\boldsymbol{D}_{\boldsymbol{j}}=$ net Duration (in minutes) of the j-th task already estimated at the design stage as a function of time that can be allocated to the task in question;

- $\boldsymbol{R} \boldsymbol{c}_{\boldsymbol{M}}=$ multiplier for the risk factor "Lack of recovery time"; it is unique and does not depend on the j-th task of the job (that is why it does have not the subscript $\mathrm{j}$ ). The designer knows the distribution of the pauses in the work shift. So, he/she can estimate the hours without adequate recovery, using the logic (and acronym) proposed by the OCRA Index, as reported in Table 3;

- $\boldsymbol{D} \boldsymbol{u}_{\boldsymbol{M}}=$ multiplier of the total net Duration of repeated tasks; it is unique and not dependent on the j-th task; Starting from $D_{j}$, the designer estimates how long a single worker will be dedicated to the assembly of the product, excluding all non-repetitive times, according to the logic (and acronym) of the OCRA method. Using Table 4, it is possible to define Dum. 
Table 2 - Values for the determination of the multiplier $R e_{M}$

\begin{tabular}{c|c|c|c}
\hline $\begin{array}{c}\text { Characteristics of } \\
\text { stereotypy }\end{array}$ & Absent & $\begin{array}{c}\text { Present with gestures or movements } \\
\text { repeated identically for } 51-80 \% \text { of } \\
\text { the time } \\
\text { or }\end{array}$ & $\begin{array}{c}\text { Present with gestures or movements } \\
\text { repeated identically for more than } 80 \% \\
\text { of the time } \\
\text { Cycle time of } 8 \text { to } 15 \text { seconds } \\
\text { or }\end{array}$ \\
\hline $\begin{array}{c}\text { Multiplier of the } \\
\text { Stereotypy }\end{array}$ & $\mathbf{1}$ & $\mathbf{0 . 8 5}$ & $\mathbf{0 . 7}$ \\
\hline
\end{tabular}

Table 3 - Values for the determination of the multiplier $R c_{M}$

\begin{tabular}{c|c|}
\hline Hours without adequate recovery & Multiplier $\mathbf{R c}_{\mathbf{M}}$ \\
\hline$<=0.5$ & $\mathbf{1 . 0 0}$ \\
\hline$<=1.0$ & $\mathbf{0 . 9 0}$ \\
\hline$<=1.5$ & $\mathbf{0 . 8 5}$ \\
\hline$<=2.0$ & $\mathbf{0 . 8 0}$ \\
\hline$<=2.5$ & $\mathbf{0 . 7 5}$ \\
\hline$<=3.0$ & $\mathbf{0 . 7 0}$ \\
\hline$<=3.5$ & $\mathbf{0 . 6 5}$ \\
\hline$<=4.0$ & $\mathbf{0 . 6 0}$ \\
\hline
\end{tabular}

\begin{tabular}{|c|c|}
\hline Hours without adequate recovery & Multiplier $\mathbf{R c}_{\mathbf{M}}$ \\
\hline$<=4.5$ & $\mathbf{0 . 5 2}$ \\
\hline$<=5.0$ & $\mathbf{0 . 4 5}$ \\
\hline$<=5.5$ & $\mathbf{0 . 3 0}$ \\
\hline$<=6.0$ & $\mathbf{0 . 2 5}$ \\
\hline$<=6.5$ & $\mathbf{0 . 1 7}$ \\
\hline$<=7.0$ & $\mathbf{0 . 1 0}$ \\
\hline$<=7.5$ & $\mathbf{0 . 0 5}$ \\
\hline$>7.5$ & $\mathbf{0 . 0 0}$ \\
\hline
\end{tabular}

Table 4 - Values for the determination of the multiplier $D u_{M}$

\begin{tabular}{|c|c|c|c|c|c|c|c|c|}
\hline $\begin{array}{c}\text { Minutes spent on repeated tasks, every } 8 \mathrm{~h} \\
\text { shift }\end{array}$ & 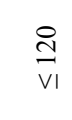 & $\frac{\infty}{\frac{\infty}{1}}$ & $\begin{array}{l}\stackrel{+}{+} \\
\stackrel{1}{1} \\
\infty\end{array}$ & $\begin{array}{l}\stackrel{8}{0} \\
\stackrel{i}{+} \\
\stackrel{+}{d}\end{array}$ & $\begin{array}{l}0 \\
\stackrel{0}{n} \\
\stackrel{1}{0} \\
\end{array}$ & $\frac{\stackrel{े}{Y}}{\stackrel{+}{i}}$ & 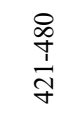 & $\begin{array}{l}\vec{\infty} \\
\stackrel{+}{\wedge}\end{array}$ \\
\hline $\begin{array}{l}\text { Multiplier of the total net Duration of } \\
\text { repeated tasks }\left(\mathrm{Du}_{\mathrm{M}}\right)\end{array}$ & $N$ & $\exists$ & $\stackrel{n}{\dddot{n}}$ & $\dddot{m}$ & ঙִ & 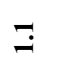 & - & $\mathscr{n}$ \\
\hline
\end{tabular}

We then proceeded to the extended formulation of the three types of Predicted Technical Actions (PTA), starting with the Basic Technical Actions (BTA). We intend them as the actions of manipulation, directly attributable to the individual components that make up the assembly. The BTA do not include actions of screwing and of handling and/or activation of the equipment. To clarify this idea, we use an example. Let us suppose that we have to assemble a threaded cylinder in its place of assembly. Using the same types of actions as those used by OCRA, the BTA will be: "pick up the cylinder", possibly "turn the cylinder" to place it correctly and "place the cylinder". We do not have to count the actions of manually screwing and activating the pneumatic screwdrivers; they will be taken into consideration in the other two types of PTA (namely, TAS and TAE). So, we have at least two actions: "pick up" and "place". Deduction leads us to say that a third action is more than likely to happen ("turn").

We hypothesized that the number of BTA is directly linked to the number of components of the assembly that will require (re-)manipulation. Starting from the concept of a two-way relationship between the two aspects, we conducted a study with reverse logic: from the results of analyses conducted on 27 different tasks or 
subtasks of assembly WorkStations (WS in Table 5), using the OCRA Index, we have identified the technical actions that reflect the concept of BTA. Therefore, we have eliminated the actions of screwing and manipulation of tools/equipment. We also took into consideration that the same component can be manipulated several times during assembly (re-manipulation). So, we "virtually" increased the number of components in order to consider this case. Starting from ATA of OCRA analysis, we get the BTA of the new method. The results are reported in Table 5.

Table 5 - Data collection for the calculation of the BTA

\begin{tabular}{|c|c|c|c|c|c|}
\hline WorkStation WS & ATA & BTA & No. of assemblies & $\begin{array}{c}\text { No. } \\
\text { components } \\
\text { per assembly }\end{array}$ & $\begin{array}{c}\text { No. } \\
\text { components } \\
\text { per assembly } \\
\text { (re- } \\
\text { manipulation) }\end{array}$ \\
\hline WS1 & 6,420 & 2,460 & 60 & 12 & 12 \\
\hline WS2 & 7,740 & 1,560 & 60 & 14 & 14 \\
\hline WS3 & 14,160 & 4,545 & 60 & 26 & 26 \\
\hline WS4 & 1,080 & 840 & 60 & 1 & 4 \\
\hline WS5 & 3,360 & 600 & 60 & 5 & 5 \\
\hline WS6 & 4,440 & 1,440 & 60 & 9 & 9 \\
\hline WS7 & 11,400 & 1,260 & 60 & 3 & 6 \\
\hline WS8 & 6,834 & 5,214 & 6 & 339 & 339 \\
\hline WS9 & 528 & 288 & 12 & 7 & 7 \\
\hline WS10 & 300 & 216 & 12 & 5 & 5 \\
\hline WS11 & 768 & 392 & 12 & 12 & 12 \\
\hline WS12 & 972 & 732 & 12 & 19 & 19 \\
\hline WS13 & 600 & 324 & 12 & 8 & 8 \\
\hline WS14 & 888 & 420 & 12 & 12 & 12 \\
\hline WS15 & 7,455 & 4,375 & 35 & 32 & 32 \\
\hline WS16 & 14,525 & 12,040 & 35 & 86 & 86 \\
\hline WS17 & 1,988 & 1,456 & 28 & 12 & 12 \\
\hline WS18 & 19,320 & 9,660 & 230 & 14 & 14 \\
\hline WS19 & 11,500 & 7,820 & 230 & 10 & 10 \\
\hline WS20 & 14,030 & 8,050 & 230 & 11 & 11 \\
\hline WS21 & 10,800 & 3,600 & 180 & 6 & 6 \\
\hline WS22 & 5,220 & 2,340 & 180 & 4 & 4 \\
\hline WS23 & 7,150 & 5,200 & 130 & 12 & 12 \\
\hline WS24 & 8,208 & 3,564 & 108 & 14 & 14 \\
\hline WS25 & 3,885 & 2,485 & 35 & 29 & 29 \\
\hline WS26 & 2,080 & 1,840 & 40 & 11 & 14 \\
\hline WS27 & 1,760 & 1,480 & 40 & 10 & 10 \\
\hline
\end{tabular}

Knowing the number of handled components in each task makes it possible to derive the number of actions per component, as reported in Table 6. To calculate 
the number of components, we have also taken into account the presence of nonconsecutive re-manipulations of the same component (e.g., same component when already assembled to another component, resulting in a third "component"). The reason is that the method will be elaborated in order to consider these possibilities.

Table 6 - Number of BTA per component, associated with a task

\begin{tabular}{|c|c|c|c|c|c|}
\hline Workstation & $\frac{B T A}{\text { Comp }}$ & Workstation & $\frac{B T A}{\text { Comp }}$ & Workstation & $\frac{B T A}{\text { Comp }}$ \\
\hline WS1 & 3.417 & WS10 & 3.600 & WS19 & 3.400 \\
\hline WS2 & 1.857 & WS11 & 2.722 & WS20 & 3.182 \\
\hline WS3 & 2.913 & WS12 & 3.211 & WS21 & 3.333 \\
\hline WS4 & 3.500 & WS13 & 3.375 & WS22 & 3.250 \\
\hline WS5 & 2.000 & WS14 & 2.917 & WS23 & 3.333 \\
\hline WS6 & 2.667 & WS15 & 3.906 & WS24 & 2.357 \\
\hline WS7 & 3.500 & WS16 & 4.000 & WS25 & 2.448 \\
\hline WS8 & 2.563 & WS17 & 4.333 & WS26 & 3.286 \\
\hline WS9 & 3.429 & WS18 & 3.000 & WS27 & 3.700 \\
\hline
\end{tabular}

Note that the number of BTA per component for WS2 is lower than 2, because some small parts are handled together so that they share the same actions.

Based on a MINITAB quick test, it is possible to observe a normal distribution of the data with:

- Mean $=3.156$

- Standard Deviation $=0.5823$

Taking a precautionary approach, we decided to set the number of BTA per component equal to the upper bound of the confidence interval of the mean at 95\%: 3.386. The definition of BTA appears to be [5]:

$B T A=3.386 \sum_{l=1}^{r} N C_{l}$

where:

$l=$ generic component that forms the assembly;

$r=$ number of types of components that make up the assembly;

$N C_{l}=$ Number of each of the Components (for example, the number of screws of the same type).

The Technical Actions of Screwing (TAS) are designed to be calculated with the following formula [6]: 
$T A S=\sum_{m=1}^{S}\left(N V_{m} A V_{m}\right)$

where:

$m=$ generic threaded component forming the assembly;

$S=$ number of types of threaded components forming the assembly;

$N V_{m}=$ number of each type of threaded component;

$A V_{m}=$ number of technical actions associated with the threaded component of the m-th type.

These types of actions are those required to perform manual screwing of components, whether they are screws, bolts, nuts or generic bodies with threads. The basic concept of the TAS is that the number of technical actions associated with the threaded component of the m-th type is directly linked to the number of threads in contact. By hypothesis, we consider two technical actions for each thread, because we can deductively suppose that this is the minimum number of actions needed in order to rotate a cylindrical body along its axis for 360 degrees.

The Technical Actions on Equipment (TAE) are the actions needed to manipulate and/or activate tools and equipment. The most practical way to consider them is by using a list, where we can insert the available instruments and equipment, the number of times that they are used and the number of associated actions. The generic formulation for TAE is the following [7]:

$T A E=\sum_{q=1}^{t}\left(N U A_{q} A A_{q}\right)$

where:

$q=$ generic available equipment;

$t=$ number of types of available equipment;

$N U A_{n}=$ Number of Uses of equipment of the $n$-th type;

$A A_{n}=$ number of technical actions associated with equipment of the $n$-th type.

Now we reconsider the basic equations of PTA and RTA:

$$
\begin{array}{ll}
P T A=\sum_{j=1}^{n}\left[\left(B T A_{j}+T A S_{j}+T A E_{j}\right) N P\right] & \text { Recall [3] } \\
R T A=\sum_{j=1}^{n}\left[C F\left(F o_{M j} P o_{M j} R e_{M j} A d_{M j}\right) D_{j}\right]\left(R c_{M} D u_{M}\right) & \text { Recall [4] }
\end{array}
$$

In conclusion, we report the generic formula of the proposed method [8]: 
$R I=\frac{\sum_{j=1}^{n}\left\{\left[3.386 \sum_{l=1}^{r} N C_{l}+\sum_{m=1}^{S}\left(N V_{m} A V_{m}\right)+\sum_{q=1}^{t}\left(N U A_{q} A A_{q}\right)\right] N P_{j}\right\}}{\sum_{j=1}^{n}\left[C F\left(F o_{M j} P o_{M j} R e_{M j} A d_{M j}\right) D_{j}\right]\left(R c_{M} D u_{M}\right)}$

where:

$j=$ generic repeated task of the upper limbs;

$n=$ number of repeated tasks in the shift.

The RI is the Risk Index/indicator, whose meaning reflects the same pattern as the OCRA Index, meaning that the two methods completely overlap and are comparable, as reported in Table 7 .

Table 7 - Risk Index levels for the new method

\begin{tabular}{|c|c|c|}
\hline RI Value & RISK LEVEL & INTERVENTION \\
$\begin{array}{c}\text { 0-2.2 } \\
\text { GREEN AREA }\end{array}$ & Acceptable & No consequence \\
\hline $\begin{array}{c}2.3-\mathbf{3 . 5} \\
\text { YELLOW AREA }\end{array}$ & $\begin{array}{c}\text { Doubtful or very } \\
\text { slight }\end{array}$ & New check; anamnestic health surveillance \\
\hline $\begin{array}{c}\text { 3.6-4.5 } \\
\text { LIGHT RED AREA }\end{array}$ & Present and slight & $\begin{array}{c}\text { Interventions of redesign of tasks and workplaces according } \\
\text { to priority. Train workers and enable health surveillance }\end{array}$ \\
\hline $\begin{array}{c}\text { 4.6-9.0 } \\
\text { MEDIUM RED AREA }\end{array}$ & Present and medium & $\begin{array}{c}\text { Interventions of redesign of tasks and workplaces according } \\
\text { to priority. Train workers and enable health surveillance }\end{array}$ \\
\hline $\begin{array}{c}\text { OvIOLET AREA } \\
\text { Intense }\end{array}$ & $\begin{array}{c}\text { Interventions of redesign of tasks and workplaces according } \\
\text { to priority. Train workers and enable health surveillance }\end{array}$ \\
\hline
\end{tabular}

To assist in the application of the method we developed an Excel tool for data entry and automated calculation of the Risk Index.

The tool is divided into five spreadsheets and we list and briefly describe them below:

- Spreadsheet "Design - BTA": its function is to allow the insertion of management, production and design data. We have to insert the net time of repeated work scheduled for the shift, the number of hours without adequate recovery, the daily/shift production, and the available production time for the considered task. In addition, we insert a series of data on the manipulated components such as component name, number of components of the same type and number of associated tools. The collected data are used for the estimation of some multipliers and for the calculation of BTA;

- Spreadsheet "TAS": to calculate the number of TAS, here we collect data on the type and number of threaded components associated with manual actions of screwing, whether performed with or without special tools. We should not 
consider the actions of manipulation and/or activation of instrumentation for screwing (we include them in the calculation of TAS);

- Spreadsheet "TAE": this is a list of tools/equipment that could be used in the assembly operations. We associate with them a certain number of standard actions for single use or, in specific cases (for example, use of a hammer), there is the possibility of detailing the number of actions based on design assumptions. The data are recalculated according to the number of uses of the same instrument over the cycle of work. Thus, we can estimate the number of TAEs;

- Spreadsheet "Results": here the results of the analysis are presented, in particular the PTA (subdivided into BTA, TAS and TAE) and the Risk Index for the dominant upper limb in optimal conditions of Strength and Posture (that is, when Strength and Posture multipliers are equal to "1");

- Spreadsheet "Scenarios Strength-Posture": this spreadsheet presents a matrix showing all combinations of Strength-Posture multiplier ( $\mathrm{Rc}_{\mathrm{M}}$ and $\mathrm{Du}$ from equation [4]), to evaluate the influence of these two factors on the Risk Index previously assessed.

A few excerpts of the use of the Excel tool (which is available, under request to the authors) are reported in following paragraph.

\section{Method implementation and validation}

To validate the new method, this section aims at demonstrating its coherence with the OCRA Index, the proposed international standard reference. We consider the dominant upper limb to be a benchmark for the OCRA Index and, therefore, the most penalizing result. When using the new method, we simulated the conditions that we had in the design phase, taking into account the real case of 27 workstations for the assembly of large industrial electronic components; that is, we did not watch any recorded movie of the tasks, rather we collected only the technical and technological information regarding the product to produce and the associated likely workstation.

In this study, the validation is based on 20 the workstations (that is, set of tasks) implying the most severe workload among the 27 workstations used to create the method. In future, an independent data set may be used to improve the strength of the validation testing, particularly in order to check/fine-tune the formula [5]. 


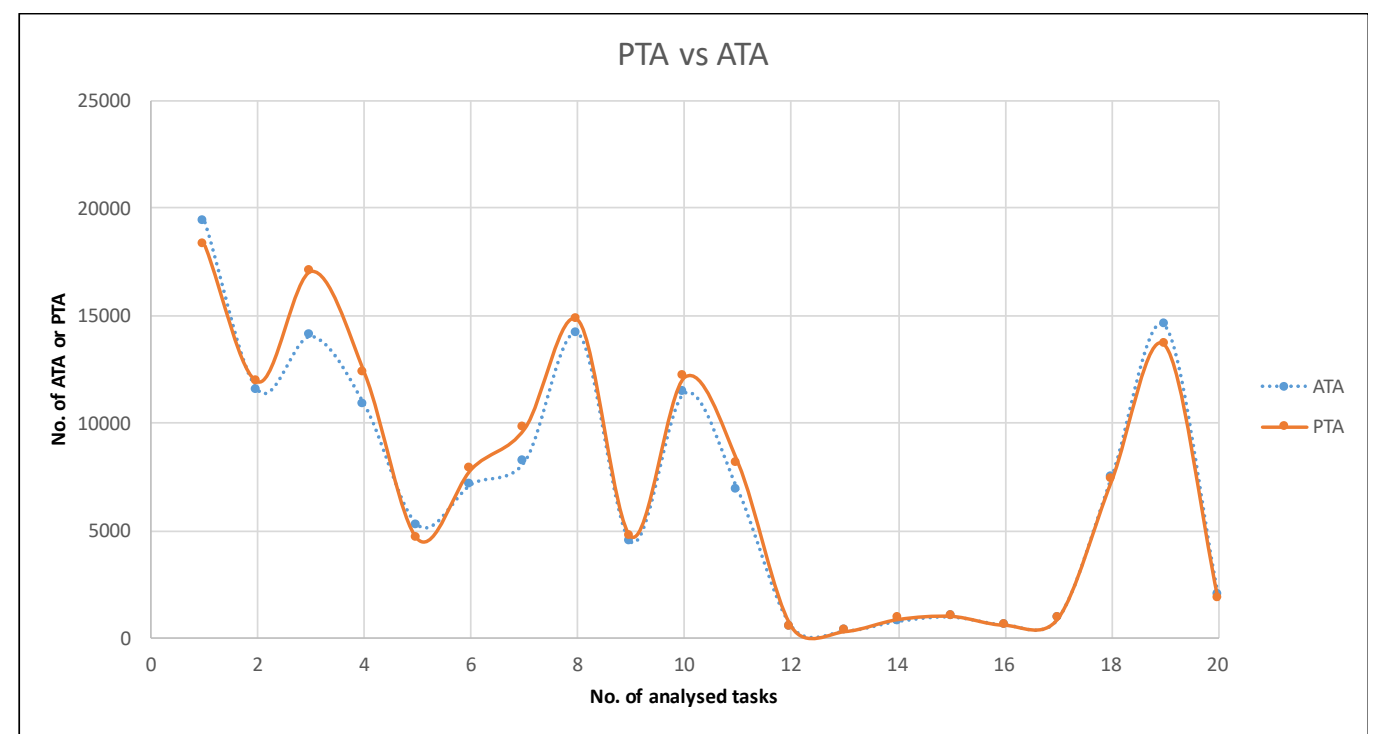

Figure 2 - Graphical comparison between ATA and PTA for the considered workstations/set of tasks

Comparing the ATA of the OCRA Index with the PTA of the new method in 20 analysed workstations, it is clear that the good overlapping of the two curves shows the ability of the proposed method, as reported in Fig. 2. The maximum recorded error is about $22 \%$, but in most cases, it reaches values of below $10 \%$. In terms of prediction at a design stage, this approximation seems to be potentially promising, and it is confirmed by Fig. 3, where we can compare the values of the Risk Index: if we consider the pertinence to different "levels" from "acceptable" to "intense") we observe really few noteworthy discrepancies, which can be considered very good, if we consider that currently whatever has to do with ULWMSD Risk Assessment is typically performed well after the design of a new product and its assembly workstation (that is, currently the designer may in principle design $100 \%$ of "unsafe" assembly stations, which would result in $100 \%$ redesign). 


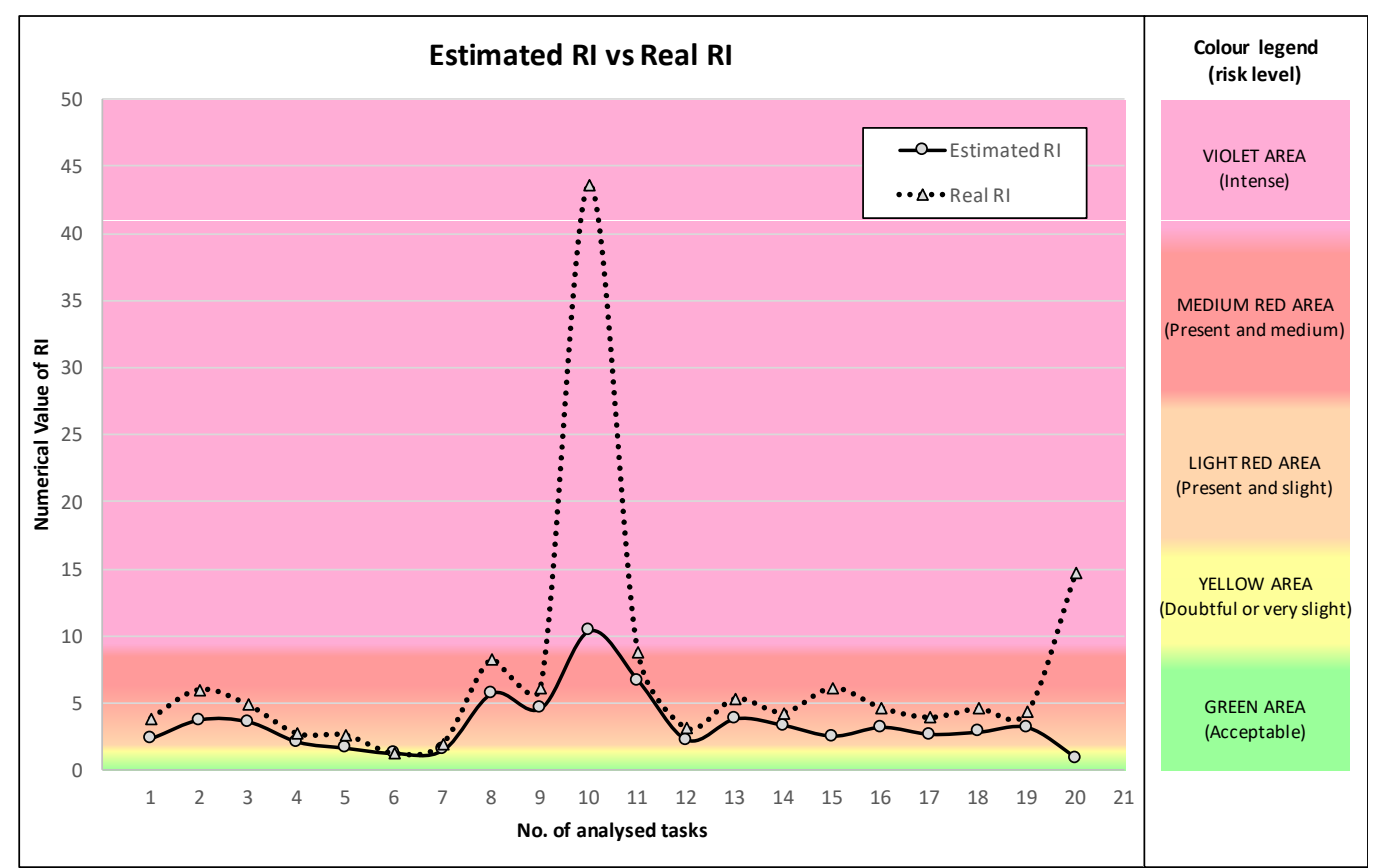

Figure 3 - Graphical comparison between estimated RI and real RI for the considered workstations/set of tasks

These significant differences are caused by the inability to predict extreme (as well as unlikely, anyway less frequent) situations related to the Force and Posture multipliers. However, the new method can immediately investigate issues related to design features. If the Risk Index is unacceptable, it will be even more unacceptable considering strength and posture. We can therefore make changes at a design stage. When we have not significant difference, the Risk Index (caused by Force and Posture multipliers) of the new method is very close to the OCRA Risk Index: the colour of risk level is the same or the closest one.

The latest considerations are corroborated by the integration of the actual values of the multipliers (from an actual analysis conducted with OCRA Index) with the result of the new method: as a consequence, the chart would change, as reported in Fig. 4. 


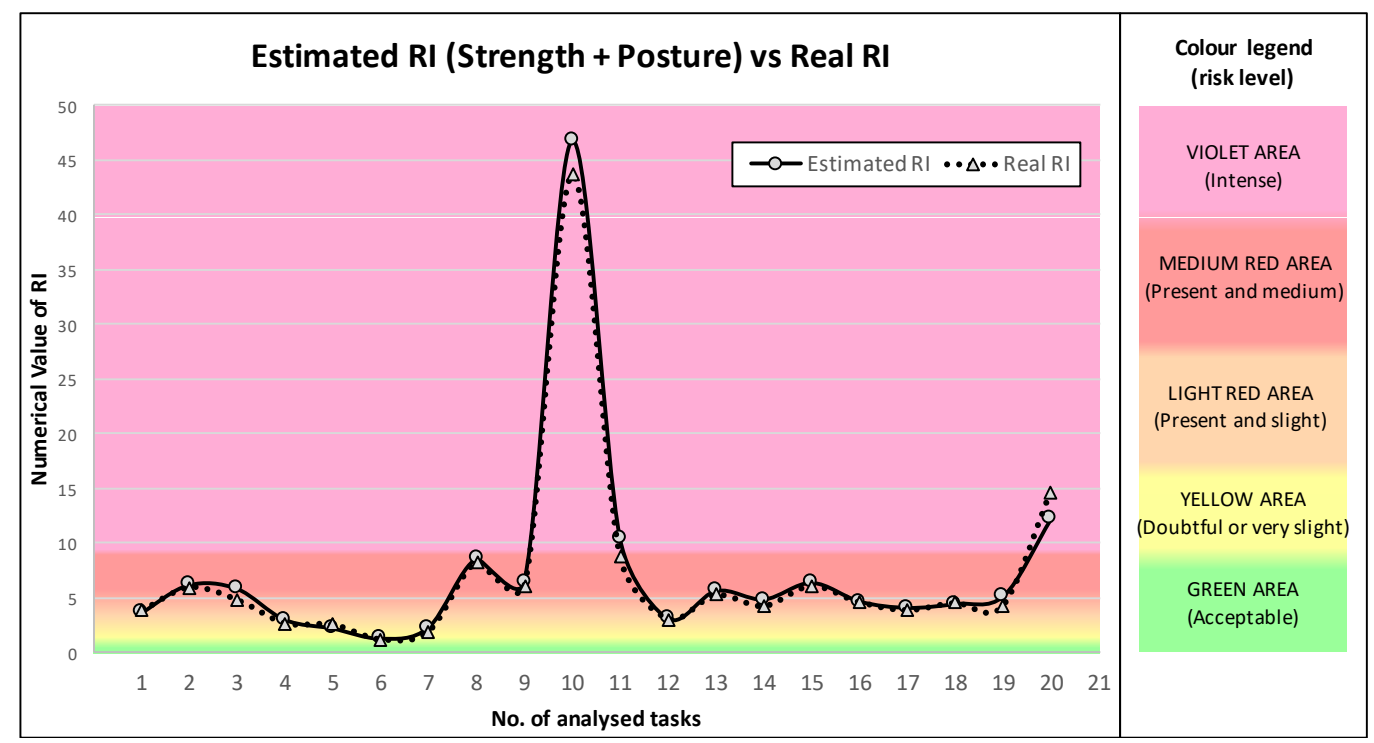

Figure 4 - Graphical comparison between estimated RI and real RI (Strength + Posture) for the considered workstations/set of tasks

Summing up, the new method it is a good approximation for this type of analysis when Force and Posture multipliers are relatively close to " 1 ". In this conditions, risk levels are properly identified by the new method.

As in the design stage, we do not have the possibility of estimating multipliers of Force and Posture; we can proceed with an assessment of the possible scenarios (for the workstations for which the designer may guess hard conditions in terms of Force and/or Posture), according to the logic proposed in Table 8. As a simple tool to help the designer, we report in Table 8 all the possible combinations of Strength-Posture multiplier ( $\mathrm{Rc}_{\mathrm{M}}$ and DuM from equation of RTA [4]), to easily adapt the RI from "optimal conditions" to harder ones. The matrix is also visually useful to clarify the impact of these two factors on the Risk Index.

Table 8 - Example of matrix of Strength-Posture scenarios 


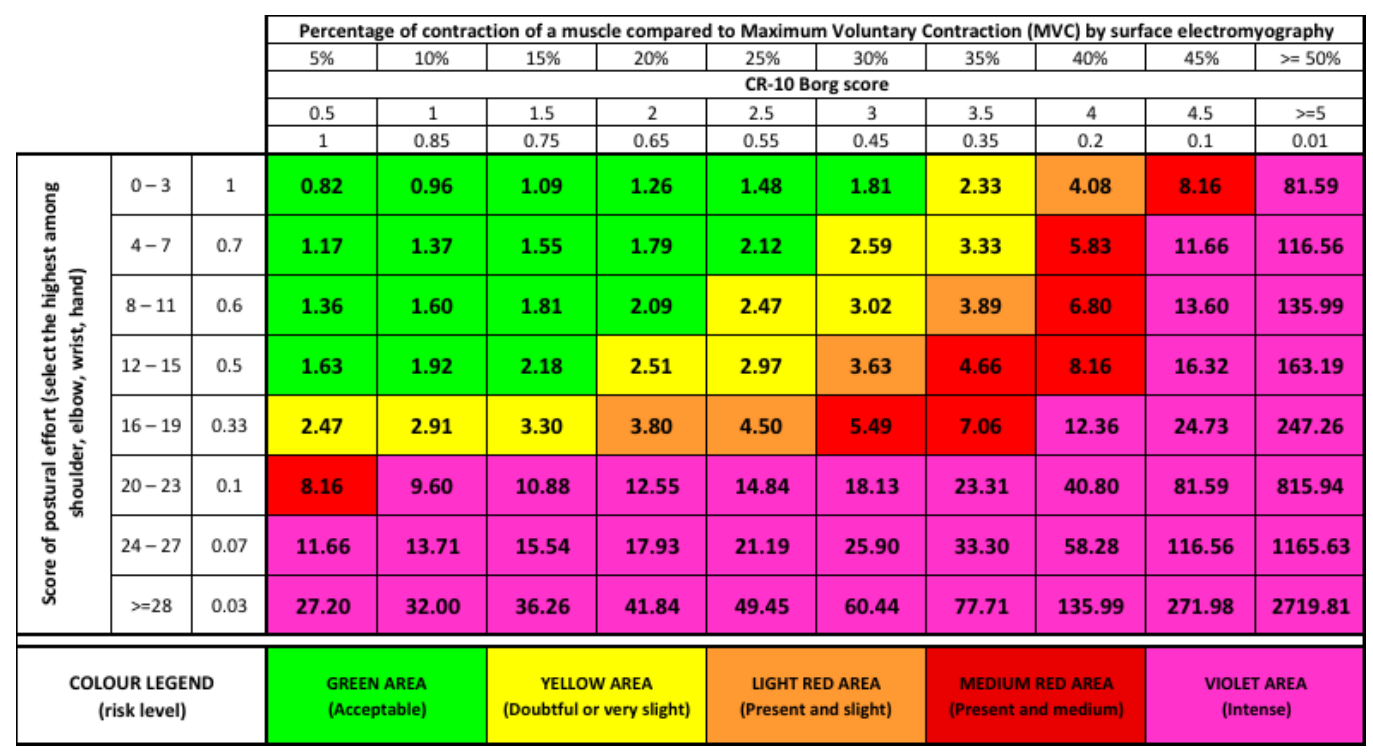

Finally, PRASAD allows the degree of acceptability of the risk to be quantified, compared to the optimal condition for the factors Force and Posture. Therefore, we are able to know how much freedom we can afford at the design stage if we do not consider these types of issues.

\section{Discussion}

The correspondence of the results of the new method with those of the OCRA Index was verified by the tests conducted. Thanks to PRASAD, we will be able to conduct risk analysis of a predictive type for products not yet in production, enabling the identification of problems and potential causes of future diseases categorized as UL-WMSDs. This capability of PRASAD is not trivial, and it is an important step towards modelling the interaction between workers and the workplace, highlighting the deep link, not only between the operator and the process, but also between the technical characteristics of the assembly and the complexity of the associated task.

PRASAD is to be used in the field of manual assembly. Summing up, we can apply it to all future tasks for the assembly of products formed by a defined number of components.

Moreover, given the basic logic of the formulation, it is possible to use the new method even in the field of application and not just in the design. By this, we mean that it is always possible to obtain an estimate according to PRASAD, even for an already existing task, for a fast mapping with a level of detail certainly superior to the classical checklist. In addition, in this context we can properly contemplate the factors Force and Posture, following the rules of the OCRA Index method: using the method in a classical way, there are no limits to the design phase. 
The key features of PRASAD can be summarized as follows:

- Rapidity: even if it is true that PRASAD adds a step to a standard design phase, if one knows the design data, the analysis only requires a few dozen minutes, which is very affordable time, particularly if compared to the time needed in case a fully set workstation has to be re-arranged in order to restore the risk to within acceptable limits;

- Quantitative management of information;

- Numerical Risk Index. This is directly comparable with the OCRA Index;

- Applicability in the design phase of a new product;

- Inclusion of the factors Force and Posture, through the creation of possible scenarios, if used in the design phase.

Furthermore, the method may also be used in the following scenarios/situations:

- Evaluating the variation of the index as a function of the available time, it is possible to assist the production management to ensure a sufficient net of productive time to minimize the Risk Index;

- The obtained information can be used for the management of personnel for Job Rotation.

The limits of the new method are:

- Used only for manual assembly;

- Inability to estimate the multipliers of Strength and Posture if used in the design phase;

- Inability to distinguish between right arm and left arm: this level of detail is typically not taken into account at a design phase. Thus, it is not a major constraint.

PRASAD is also improvable through testing on an independent data set in order to calibrate the coefficient in the equation of BTA [5].

A promising research stream may be related to multipliers of Force and Posture that we cannot predict.

Taking into account the multiplier "Strength", we know that the two possible ways are using the Borg CR-10 and surface electromyography. The former is a method based on interviews with one or more operators, who evaluate the muscular efforts through adjectives (light, moderate, strong, very strong, maximum), corresponding to specific numerical values used in the usual analysis with the OCRA Index. As the number of interviewed people increases, the reliability of PRASAD grows. The latter, on the other hand, is based on data provided by sensors positioned at skin level that can indicate the percentage of 
contraction of a muscle compared to Maximum Voluntary Contraction (MVC). This technology is very expensive and is used only when it is financially sensible. In practice, currently the majority the analyses conducted for identifying ULWMSDs exploit the Borg CR-10. Nonetheless, at a design stage we have nothing available, such as the Borg CR-10. A future development to fill this limitation is to create a "Database of Strength": through statistical analysis, we should submit a sample of workers to standard technical actions, that is, operations that use both tools and strength. The adjective "standard" describes actions/operations with specific features that are not affected by too many variables. This is the case with screwing with wrenches (dynamometric and not) with determined tightening torque and distance of the holding point. The "Database of Strength" is, in the specific case considered, a list of torque-arm combinations corresponding to a specific numerical value of the Borg CR-10, obtained by averaging the values of interviews on operators. The concept can be extended to any operation univocally identified, corresponding to a given intensity value of strength.

In this way, our contribution to literature is about opening a potentially new "research stream", to fill the existing void.

The idea of a "Database of Strength" is related to the Strength-Posture scenarios. Actually, we use scenarios because we cannot consider strength and posture at a design stage. When we will able to predict the Force level using the "Database of Strength", the value will be included directly in the equation method (as for OCRA). In this way, scenarios will only depend on postures.

For the Posture multiplier, a future development in the application of the method in the design phase is to integrate the simulation in a graphical environment on virtual mannequins. The simulation of the articular movements would enable the study of awkward postures. A similar approach has been developed by the Fiat Chrysler Automobiles group (FCA) (Ghibaudo and Spada, 2014) and it is part of the world of human-centred design.

In order to use PRASAD for a conventional analysis (that is, not at a design stage), where we have the ability to study a real task, a fundamental support would be the use of a set of accelerometers. The information from these sensors would allow a much more rapid and accurate study than the classic modus operandi, which consists of the observation of a video recording, aimed at the study of awkward postures.

In conclusion, PRASAD represents an important innovation in the context of risk assessments of UL-WMSDs, enabling an estimate from the early planning stages of a new product and the associated workstation: it potentially enables a design that is aware of the implications of ergonomics, together with associated (future) cost savings (Hendrick, 2003; Miles and Swift, 1992; Neumann and Dul, 2010).

\section{Credits and acknowledgements}

The authors wish to thank Luca Dellera, MSc, for his valuable contribution to this work. 


\section{References}

American Conference of Governmental Industrial Hygienists (ACGIH), 2004. Threshold Limit Values for Chemical Substances and Physical Agents Biological Exposure Indices 2004. ACGIH, Cincinnati, United States.

Bhattacharya, A., McGlothlin J.D., 2011. Occupational Ergonomics: Theory and Applications. CRC Press, Boca Raton, Florida, US.

Banca d'Italia, 2016. Economie regionali - L'economia delle regioni italiane nel 2015. https://www.bancaditalia.it/pubblicazioni/economie-regionali/index.html. (accessed 2017-05-20).

BSI, 2003. BS EN 1005-2:2003+A1:2008 Safety of machinery. Human physical performance. Manual handling of machinery and component parts of machinery. http://shop.bsigroup.com/ProductDetail/?pid=000000000030179205. (accessed 2016-01-07).

Colombini, D., Occhipinti, E., Fanti, M., 2013. Il Metodo OCRA per l'Analisi e la Prevenzione del Rischio da Movimenti Ripetuti. Collana Salute e Lavoro, Franco Angeli Editore, Milan, Italy. (In Italian)

Legislative Decree 81/08, 2008. Legislative Decree on Occupational Health and Safety. (In Italian)

Ghibaudo, L., Spada, S., 2014. FIAT. La corretta progettazione del posto di lavoro: dalla simulazione virtuale immersiva alla realizzazione, attraverso la partecipazione dell'operatore di linea. Proceedings of the International Seminar "La prevenzione del rischio da sovraccarico biomeccanico", Milan, Italy. (In Italian)

Hendrick, H.W., 2003. Determining the cost-benefits of ergonomics projects and factors that lead to their success. Applied Ergonomics, 34, 419-427.

Hervet, C., Vallerey G., 2001. Les facteurs de risque biomecaniques ou exogenes directs dans l'approche des TMS - Etude en milieu industrielle avec l'application de la méthode OREGE de l'INRS. Proceedings of the SELF-ACE Conference, Montréal, Canada. (In French)

INAIL, 2013. Rapporto Annuale 2013. http://www.inail.it/internet/salastampa/SalastampaContent/NumerieStatistiche/a 
rchivioRapportiAnnualiNazionale/p/DettaglioRapportiAnnuali/index.html?wlpn ewPage contentDataFile=UCM PORTSTG_076070\&_windowLabel=newPage (accessed 2016-01-07). (In Italian)

ISO 11228-3, 2007. Ergonomics - manual handling - Part 3: handling of low loads at high frequency. http://www.iso.org/iso/catalogue detail.htm?csnumber=26522. (accessed 201601-07).

ISO/TR 12295, 2014. Ergonomics - application document for International Standards on manual handling (ISO 11228-1, ISO 11228-2 and ISO 11228-3) and evaluation of static working postures (ISO 11226). http://www.iso.org/iso/home/store/catalogue tc/catalogue_detail.htm?csnumber $=51309$. (accessed 2016-01-07).

Loch, C.H., Kavadias, S., 2008. Handbook of new product development management. Routledge, London, UK.

McAtamney, L., Corlett, E.N., 1993. RULA: A survey method for investigation of work-related upper limb disorders. Applied Ergonomics, 24(2), 91-99.

Madhi, M.M., Majid, M., Javad, F., 2013. Investigating the correlation of OCRA Index, Strain Index and ACGIH HAL methods for assessing the risk of upper limb musculoskeletal disorders. Journal of Ergonomics, 1(2), 63-71.

Miles, B.L., Swift, K.G., 1992. Design for Manufacture and Assembly. Manufacturing Engineer, October, 221-224.

Moore, J.S., Garg, A., 1995. The strain index: a proposed method to analyze jobs for risk of distal upper extremity disorders. American Industrial Hygiene Association Journal, 56(5), 443-458.

Neumann, W.P., Dul, J., 2010. Human factors: spanning the gap between OM \& HRM. International Journal of Operations \& Production Management, 30 (9), 923-950.

Sala, E., Torri, D., Tomasi, C., Apostoli, P., 2010. Stima del rischio da sovraccarico biomeccanico dell'arto superiore condotta, con l'impiego di più metodi di analisi, in diversi settori manifatturieri. Giornale Italiano di Medicina del Lavoro ed Ergonomia, 32(2), 162-73. (In Italian) 
Salvendy, G., 2001. Handbook of Industrial Engineering: Technology and Operations Management, third edition. John Wiley \& Sons, Hoboken, New Jersey, USA.

Schneider, S., 1995. OSHA's draft standards for prevention of work-related musculoskeletal disorders. Applied Occupational and Environmental Hygiene, $10(8), 665-674$.

Simoneau, S., St-Vincent, M., Chicoine, D., 2003. Work-related Musculoskeletal Disorders (WMSDs): A Better Understanding for More Effective Prevention. Practical Guide funded by IRSST and the A.S.P. Métal-Électrique, Québec City, Canada. 